\title{
EDITORIAL
}

\section{Human Genetic Research in Pakistan: Challenges and Way forward}

Syed Muhammad Imran Majeed, Aisha Mohyuddin

The 90s ushered in the era of molecular genetics in Pakistan. Our centuries' old tradition of consanguineous marriages, resulting in the availability of large, inbred families with inherited disorders, proved to be a goldmine for geneticists, working to discover new genes and their functions. A multitude of novel genes with previously unknown functions were discovered through genetic linkage analysis, a technique that compares the segregations of DNA markers in normal and affected family members to pinpoint the region that contains the suspect gene. The first few landmark publications on linkage analysis in genetic diseases, from Pakistan, identified only the regions harboring the suspected disease genes. ${ }^{1,2}$ As the field advanced, disease causing mutations segregating in affected family members were identified through Sanger DNA sequencing of candidate genes in the linked region. In the last decade, the advent of high through put techniques such as whole exome analysis and animal disease modeling, functional genomics studies became an integral of part of such genetic studies. In addition, bioinformatics tools were developed for predictive modeling of the effect of mutations on protein structure.

The analysis of a single large multi generational family with a genetic disorder could provide the same information that would be obtained from many small nuclear families, as usually found in developed countries. This allowed Pakistani researchers to attract collaborators from Universities around the world. DNA samples of numerous Pakistani families were sent to labs across the world for analysis, many times accompanied by a PhD student who would typically spend around six months working on those families. Universities developed efficient pipelines, whereby students would find families with genetic diseases, extract DNA and carry out linkage analysis and, in some cases, identify the gene mutations using Sanger sequencing. This led to a significant increase in the number of publications on genetics, from Pakistan. However, despite all the good work carried in the country, no credible effort had been made to build national capacity to carry the work beyond initial mutation screening.

We lack the ability to conduct good quality high through put-omics analysis and animal model studies within the country. There are several reasons for this. Firstly, the cost of such research is prohibitive. While some institutes have invested in next generation sequencing platforms, these machines are largely underutilized due to high cost of consumables. Lack of adequate funding for reagents, required for genomic, transcriptomic and proteomic studies, is a major road block. Secondly, the ease in attracting foreign collaborators to carry out the functional studies in their labs, has made many Pakistani researchers complacent, often, they are happy to be co-authors in research papers without having to go through the pains to set up the required laboratory facilities. Lastly, the bureaucratic processes and red tape, especially in public sector Universities, make procurement of chemicals and consumables, tedious and time consuming, resulting in demotivation of researchers and faculty. There is a need to address these issues, if we wish to move towards self-sufficiency in conducting high level functional genomics and stem the flow of biological samples from Pakistan.

While genetic studies in Pakistan have resulted in the discovery of many novel genes, the benefit of these studies is yet to trickle down to the patients. The willingness of the affected families to participate in these studies is crucial. Many affected families belong to far flung rural areas and have no understanding of their disease, how it is inherited or the implications of participating in such research. It is unlikely that families participating in these studies have any immediate benefits and they should be informed at the time of recruitment using common language which they are able to understand. The role of Institutional Ethics and Review Boards, for the protection of study participants and their rights, needs to be strengthened. It is important not to abandon these families after sample collection but to relay the results of the study and counsel them regarding their future options. 
Despite the rapid advances in genetic medical knowledge, our population has yet to reap its benefits. A small step in right direction is the Compulsory Blood Test of the Relatives of Thalassemia Patient Bill-2017, which makes it compulsory for couples to get tested before marrying. However, the scarcity of gene testing facilities and healthcare professionals trained in clinical genetics is an impediment to the implementation of this bill in the true spirit. It is becoming imperative to educate our healthcare professionals regarding the application of genetics to medical practice. Clinical genetics and its related competencies need to be recognized as medical specialties in the country, before they can be introduced into mainstream clinical practice to improve health outcomes of our affected families.

\section{Editor-in-Chief}

How to cite this:Majeed SMI, Mohyuddin A.Human Genetic Research in Pakistan: Challenges and Way forward. Life and Science. 2021; 2(1): 1-2. doi:http://doi.org/10.37185/LnS.1.1.182

This is an Open Access article distributed under the terms of the Creative Commons Attribution License (http://creativecommons.org/licenses/by/4.0), which permits unrestricted use, distribution, and reproduction in any medium, provided the original work is properly cited.

\section{REFERENCES}

1. Faiyaz ul Haque M, Uhlhaas S, Knapp M, Schüler H, Friedl W, et al. Mapping of the gene for X-chromosomal split-hand/split-foot anomaly to Xq26-q26.1. Hum Genet. 1993; 91: 17-9.

2. Veske A, Oehlmann R, Younus F, Mohyuddin A, Müller-Myhsok B, Mehdi SQ, et al. Autosomal recessive non-syndromic deafness locus (DFNB8) maps on chromosome 21q22 in a large consanguineous kindred from Pakistan. Hum Mol Genet. 1996; 5: 165-8. 